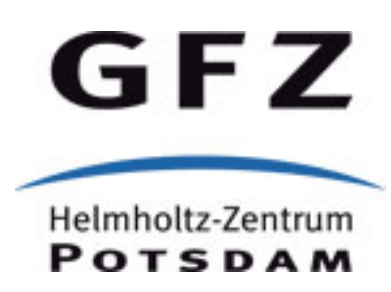

Originally published as:

Wiese, B., Wagner, F. M., Norden, B., Maurer, H., Schmidt-Hattenberger, C. (2018): Fully coupled inversion on a multi-physical reservoir model - Part I: Theory and concept. - International Journal of Greenhouse Gas Control, 75, pp. 262-272.

DOI: http://doi.org/10.1016/j.ijggc.2018.05.013 


\title{
Fully Coupled Inversion on a Multi-Physical Reservoir Model - Part I: Theory and Concept
}

\author{
Bernd U. Wiese ${ }^{\mathrm{a}, *}$, Florian M. Wagner ${ }^{\mathrm{b}, 1}$, Ben Norden ${ }^{\mathrm{a}}$, Hansruedi Maurer ${ }^{\mathrm{c}}$, Cornelia Schmidt-Hattenberger ${ }^{\mathrm{a}}$ \\ ${ }^{a}$ GFZ German Research Centre for Geosciences, Section 6.3 Geological Storage, Potsdam, Germany \\ ${ }^{b}$ University of Bonn, Steinmann Institute, Department of Geophysics, Bonn, Germany \\ ${ }^{c}$ ETH Zurich, Institute of Geophysics, Zurich, Switzerland
}

\begin{abstract}
State of the art reservoir monitoring delivers numerous property data with high resolution. Especially the consistent interpretation of pressure data with different geophysical methods requires multi-physical modelling and inversion workflows. Such a workflow is developed based on the reservoir monitoring concept of the Ketzin pilot site for $\mathrm{CO}_{2}$ storage, Germany. The workflow consists of three physical models, (i) a single phase hydraulic model, (ii) a multiphase $\mathrm{CO}_{2}$ migration model and (iii) a geoelectrical model. Calibration is carried out to match observation data groups hydraulic pressure, $\mathrm{CO}_{2}$ pressure, $\mathrm{CO}_{2}$ arrival time and geoelectrical cross-hole observations. Calibration parameters are spatially distributed hydraulic permeability and porosity, compressibility, the relative permeability function and the geoelectrical saturation exponent. Geoelectrical measurements with low coverage that can not be inverted with traditional methods could be included, since the multiphysical reservoir model acts as physical regularisation. The indirect nature of geophysical data is overcome by implementation of petrophysical relations between permeability and porosity and between $\mathrm{CO}_{2}$ saturation and electrical resistivity. Stability against field data is increased by reducing the impact of structural noise through preprocessing the observation data. Stability against the overparameterisation is added by Tikhonov regularisation and singular value decomposition, the latter combined with super parameter definition reducing the problem dimensions and simulation time by three quarters. A synthetic case study demonstrates that the model resolves the spatial permeability and identifies the petrophysical relation between $\mathrm{CO}_{2}$ saturation and electrical resistivity. The weighting scheme balances different observation data groups and measurement intervals. The model to measurement misfit is reduced proprotionally for all observation data groups, while the geoelectrical data are most difficult to match.
\end{abstract}

Keywords: Multi-physical, Hydrogeophysical, Inverse reservoir modelling, Weighting, Pumping tests, Pressure, Geoelectrical monitoring, Barrier, Mulit-layer $\mathrm{CO}_{2}$ storage, Ketzin

\section{Introduction}

A thorough comprehension of a geological reservoir and of changes within the reservoir is required to ensure safe and reliable storage and is demanded by regulating authorities (Jenkins et al., 2015). Numerical flow and transport simulations support reservoir comprehension and provide predictive capabilities to accompany operational decisions. Traditionally, flow model calibration is performed in the frame of a manual history matching process, where selected parameters are adjusted by the experienced

\footnotetext{
${ }^{*}$ Corresponding author: Bernd U. Wiese

Email address: wiese@gfz-pot sdam. de (Bernd U. Wiese)

${ }^{1}$ Previously at ${ }^{\mathrm{a}}$ and ${ }^{\mathrm{c}}$
}

modeller to match corresponding field observations. Several $\mathrm{CO}_{2}$ storage related field studies have demonstrated that manual history matching produces good fits of arrival times (e.g. Kempka et al., 2010) and reservoir pressure (e.g. Lengler et al., 2010; Pamukcu et al., 2011b; Strandli et al., 2014). However, manual history matching approaches are time-consuming, not suitable for large numbers of parameters, and poor in the assessment of uncertainty (Oliver and Chen, 2010). Inverse reservoir flow models overcome these problems and are therefore applied for oil reservoirs (e.g. Floris et al., 2001; Li et al., 2003; Seiler et al., 2009) but rarely for $\mathrm{CO}_{2}$ storage (Class et al., 2015; Doetsch et al., 2013).

State of the art reservoir monitoring is not any more based on pressure data only but extended by an increas- 
ing number of geophysical methods. Multi-physical modelling and inversion concepts are required to generate data consistent as well as plausible reservoir realisations. Electrical resistivity tomography (ERT) is a well established method in near-surface geophysics (Binley and Kemna, 2005; Loke et al., 2013) and has also received consideration as a permanent reservoir monitoring tool due to its high sensitivity to fluid displacement processes with comparably high spatial and temporal resolution (Ramirez et al., 2003; Christensen et al., 2006).

To this end, several near-surface applications in the emerging field of hydrogeophysics (Binley et al., 2015) have successfully demonstrated the inclusion of ERT data within coupled hydrogeophysical inversion frameworks to directly estimate hydrogeological parameters of interest (e.g. Hinnell et al., 2010; Kowalsky et al., 2011; Herckenrath et al., 2013; Camporese et al., 2015). Since, to date, only three $\mathrm{CO}_{2}$ storage sites are equipped with permanent electrode installations worldwide, namely the Cranfield site in Mississippi, USA (Carrigan et al., 2013), the Ketzin site in Germany (Schmidt-Hattenberger et al., 2016), and the Hontomín site in Spain (Vilamajó et al., 2013), we could not find previous studies, where geoelectrical data are directly used to constrain $\mathrm{CO}_{2}$ reservoir simulations.

Petrophysical relations allow to transform geoelectrical tomograms into distributions of $\mathrm{CO}_{2}$ saturation, although this process is known to be associated with inversionrelated uncertainties (Yang et al., 2014). Direct multiphysical integration requires high quality data and realistic model assumptions otherwise the petrophysical relations may be transferred into unrealistic model parameters. The problem gains importance with the number of integrated datasets. On the other hand, multi-physical modeling has the methodological advantage that no minimum geoelctrical coverage is required since the multiphase reservoir model provides an effective regularisation.

It is not satisfying that the reservoir model and each geophysical dataset are inverted separately and compared, again manually, at a later stage (Chadwick and Noy, 2015; Luith et al., 2015; Zhu et al., 2015). A notable exception is the work of Doetsch et al. (2013). The authors invert ERT data to obtain a time-dependent resistivity distribution. In a second inversion step, the flow model is calibrated using gas tracer data and the previously obtained resistivity distribution. The intermediate step of a conventional resistivity inversion was introduced because the fully coupled inversion of ERT measurements impaired convergence, possibly due to data quality limitations or structural noise that is inherent to a model representation of field conditions. Doetsch et al. (2013) conclude that fully coupled reser- voir model inversions including time-lapse ERT data for will be an important follow-up to their work. Rinaldi and Rutqvist (2013) already run a fully coupled multi-physical model combining a $\mathrm{CO}_{2}$ flow model with geomechanical deformation but calibrate it to ground uplift data only. In the present paper a multi-physical framework is developed in which multiple physical models are inverted fully coupled (i.e. without manual result comparison or intermediate inversion steps).

The framework consists of three components: (i) the multi-physical reservoir model that generates simulated values for corresponding measurements, (ii) the constraining conditions that are defined based on field measurements (iii) the inversion framework that minimises the misfit between simulated values and field measurements.

The term hydrogeophysical modelling is often used in near surface applications that are coupled to hydraulic models. Due to the greater depth and the integration of a multiphase reservoir model in the present work, we prefer to use the term multi-physical reservoir modelling as it appears to be more intuitive to geologists and the $\mathrm{CO}_{2}$ community.

The first part of this two-part paper describes the multiphysical workflow that is developed with emphasis to stability, especially with regard to typical field data errors. It includes the petrophysical coupling concept, data pretreatment with reduction of structural noise, objective function weighting, and the reduced order inversion concept. A synthetic case study following Ketzin operation, measurement structure and well based stratigraphy is inverted to assess convergence behaviour and parameter identifiability. The second part of the paper comprises the case study on field data, in which the workflow is applied to the multi-physical dataset of the Ketzin test site for $\mathrm{CO}_{2}$ storage and conclusions on the reservoir is drawn (Wagner and Wiese, 2018, this issue).

\section{Multi-physical reservoir model}

The integrated modelling approach developed and applied in this study is depicted in Figure 1. Starting point of the workflow is a conceptual geological model based on Beutler (2002) that consists of a high permeable sandstone facies and a low permeable mudstone facies. The model permeability is layerwise isotropic as wellbore measurements suggest only weak vertical permeability constrasts (Norden et al., 2010). Further, vertical anisotropy is insensitive as the flow direction is predominantly horizontal. The initial flow and migration of $\mathrm{CO}_{2}$ is simulated with a homogeneous permeability for each of both facies. The 
hydraulic simulation relies only on the permeability field and generates hydraulic pressure. The multiphase simulation additionally requires porosity, relative permeability and capillary pressure and generates the $\mathrm{CO}_{2}$ saturation distribution over time and generates arrival times and $\mathrm{CO}_{2}$ pressure. The flow model and the multiphase model share the same model grid, permeability and wells. The geoelectrical simulation includes a petrophysical transformation of the $\mathrm{CO}_{2}$ saturation into reservoir resistivity and solves for the measured changes in apparent resistivity with different electrode configurations. Four types of data are generated by the three models, compared to their corresponding observations, weighted and transformed to the objective function. The regularisation is calculated based on the deviation from the initial parameter field (no connection arrow shown in Figure 1) and included as a fifth type of data to the objective function.

\subsection{Geological model}

The geological model represents the Stuttgart Formation at the Ketzin anticline (Figure 2). The models horizontal extent is $5 \times 5 \mathrm{~km}$ and the thickness is $90 \mathrm{~m}$. Due to the anticlinal shape, the depth ranges between $554 \mathrm{~m}$ and $956 \mathrm{~m}$ below ground level. The model consists of two facies types, a sandstone facies with high hydraulic permeability and potentially good reservoir properties and a mudstone facies with poor reservoir properties (Förster et al., 2006) with permeability smaller than $1 \mathrm{mD}$. The facies distribution is simplified from a multi-layered fluvial channel system (Norden et al., 2010) to four horizontal layers with spatially variable permeability. The geological model follows the shape of the anticline and honours the facies found as intersected by the Ketzin wells.

In wells Ktzi200 and Ktzi201, four sandstone layers are present. Layers 1 and 2 (Figure 2) are the main reservoir layers and have a model thickness of $6 \mathrm{~m}$ each. These are separated by a $1.25 \mathrm{~m}$ thick anhydritic layer (layer Anh). To the north, in Ktzi202, only one sandstone layer is found. Stratigraphically, it is located at the mean depth of layers 1 and 2 and is hydraulically connected to layer 2. The interface between both regions is assumed to be curve-shaped as depicted in Figure 2. Below layer 2 and 2a, a mudstone facies of about $9 \mathrm{~m}$ is present followed by another sandstone layer with a model thickness of $6 \mathrm{~m}$ (layer 3). The lowest sandstone layer (layer 4) has a model thickness of $2 \mathrm{~m}$ and is located $10 \mathrm{~m}$ above the lower model boundary.

The mean effective permeability is derived from field measurements of horizontal permeability at different ver- tical positions (Norden et al., 2010) at the wellbores. These are used to constrain the mean horizontal permeability at the wellbores. The constraint is introduced via a ratio between the different wellbores instead of native observations because previous reservoir models show that the measured wellbore permeabilities are about one order of magnitude higher than the effective reservoir permeabilities (Wiese et al., 2010; Lengler et al., 2010; Kempka et al., 2010; Pamukcu et al., 2011a). The ratio for layers 3 and 4 are further reduced to one third of the measured value since both layers contain more clay than layers 1 and 2 and recent measurements suggest the permeability discrepancy occurs because the impact of the clay content is underestimated in the permeability measurements ((Zemke and Liebscher, 2017) and Norden, personal communication).

The underlying assumption that leads to using ratios is that within each layer the clay content affects permeabilities in a similar manner. The reduced permeability in layer 3 and 4 is reasonable since the simulated $\mathrm{CO}_{2}$ content would be much higher than observed PNG measurements in both observation wells Ktzi200 and Ktzi202 (Baumann et al., 2014).

\subsection{Porosity and permeability characteristics}

The geological context of the sandstone facies suggests a maximum permeability of $1000 \mathrm{mD}$ (Norden and Frykman, 2013). The porosity is coupled to permeability using one empirical function for each facies from Fig. 15 in Norden and Frykman (2013). The main permeability range of the sandstone with 10,100 and $1000 \mathrm{mD}$ corresponds to porosities of 14,21 and $31 \%$, respectively. However, the correlation coefficient $\mathrm{R}^{2}$ is only 0.66 and 0.59 for sandstone and mudstone wherefore for a given porosity the permeability may vary by up to one and two orders of magnitude for sandstone and mudstone, respectively (Norden and Frykman, 2013).

The model grid discretisation is $10 \times 10 \mathrm{~m}$ in horizontal direction in the near-wellbore area, gradually increasing to $50 \times 50 \mathrm{~m}$ close to the boundary. The sandstone layers $1,2,2 \mathrm{a}$ and 3 have a vertical discretisation of $1 \mathrm{~m}$, layer 4 has a vertical discretisation of $2 \mathrm{~m}$. The observation wells are screened at different layers. Well Ktzi200 is screened to layers 1,2, and 4, well Ktzi201 is screened to layers 1, 2, and 3, and well Ktzi202 is screened to layers $2 \mathrm{a}$ and 3 . The field generatation interpolates pilot points to permeability and porosity distributions using linear radial basis functions, that allow for distributions with local maxima and minima that are not necessarily located at the pilot point positions. The fields are generated on 


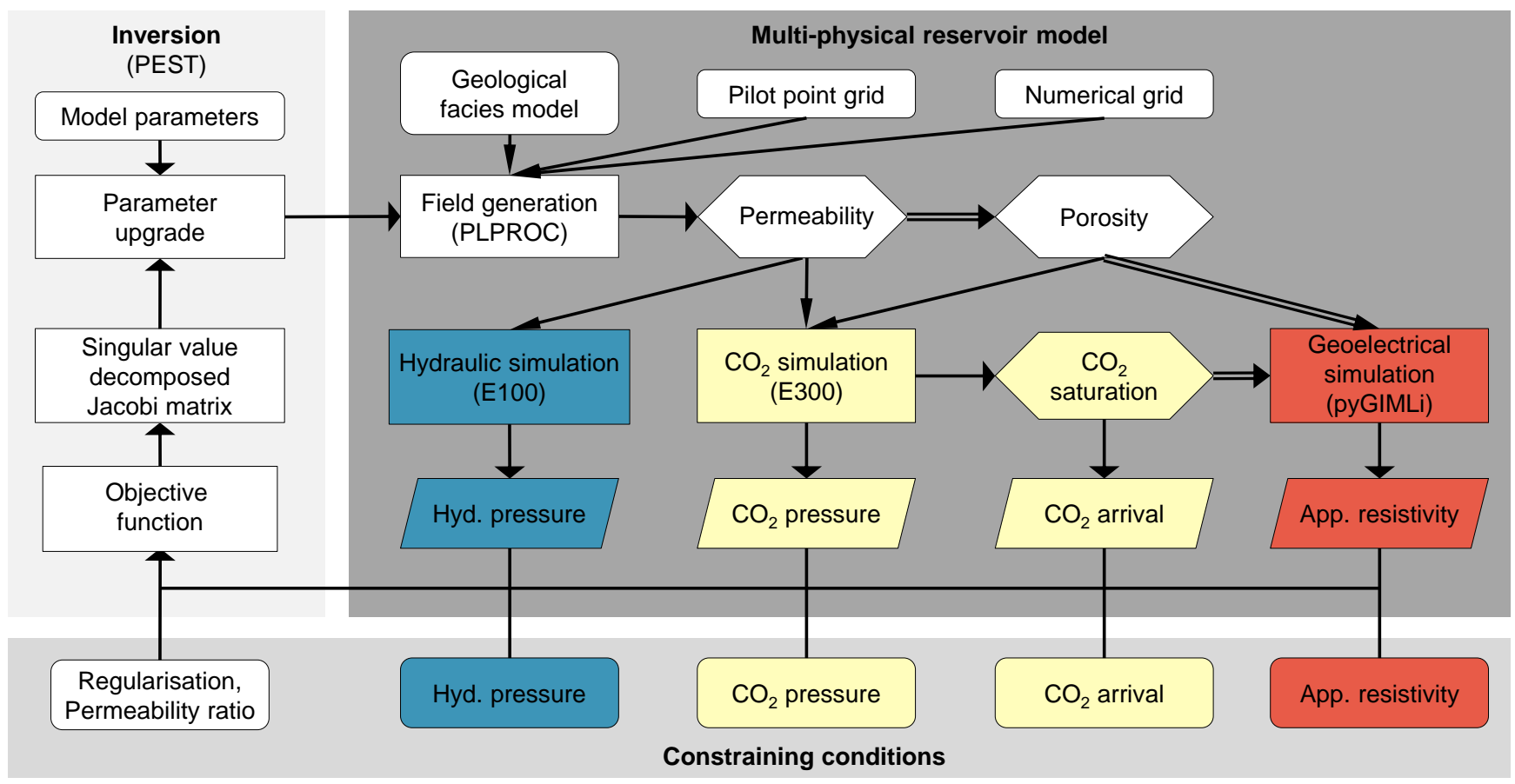

Figure 1: Main workflow components illustrating the integrated multi-physical modelling and inversion approach. Solid arrows indicate data transfer and transformation, double lined arrows indicate petrophysical conversions. Round cornered field indicate user supplied input, rectangles indicate a operations, hexagons indicate parameter fields on the eclipse grid and parallelograms indicate model generated time series. Blue, yellow and red fields show hydraulic, $\mathrm{CO}_{2}$ and geoelectrical data, respectively.

a cartesian grid that forms the computational grid for the hydraulic and the $\mathrm{CO}_{2}$ migration model. The geoelectrical simulation is carried out on an unstructured tetrahedral grid.

\subsection{Hydraulic model}

The reservoir has a temperature of $34^{\circ} \mathrm{C}$ and a brine salinity of $230 \mathrm{~g} / \mathrm{l}$ (Würdemann et al., 2010). Pressurevolume-temperature properties of $\mathrm{CO}_{2}$ and brine, including solubility of $\mathrm{CO}_{2}$ in brine, are calculated based on the equation of state by Peng and Robinson (1976). The upper and lower model facies are representing no-flow boundaries, in horizontal direction lateral flow is facilitated by application of a pore volume multiplier. Hydraulic simulation is based on a subset of the $\mathrm{CO}_{2}$ migration model formed by the same model grid, boundary conditions, intrinsic permeability, brine viscosity. Simulations are carried out with E100, a blackoil reservoir simulator (Schlumberger, 2015).

\section{4. $\mathrm{CO}_{2}$ migration model}

$\mathrm{CO}_{2}$ migration is simulated with the compositional reservoir simulator E300 (Schlumberger, 2015). Relative permeabilities are based on unpublished core measurements as used in previous models (Lengler et al., 2010;
Kempka et al., 2010) and parameterised using a BrooksCorey formulation

$$
\kappa_{r, i}=\left(\frac{s_{i}-s_{r, i}}{1-s_{r, i}-s_{r, j}}\right)^{n_{i}} C_{i}
$$

with $\kappa_{r, i}$ as the relative permeability, $s_{i}$ as saturation, $s_{r, i}$ as residual saturation, respectively. The equation is applied for both, aqueos and gaseous phases with $i$ as the actual phase an $j$ the other phase, respectively.

The constant $C_{i}$ scales the endpoint for full saturation of the respective phase. Theoretically this should be 1 , but is often lower in simulations as fully saturated non wetting conditions are typically not reached.

The capillary pressure follows a so called lambda formulation

$$
p_{c}=p_{e}\left(\frac{s_{w}-s_{r, w}}{1-s_{r, w}}\right)^{\frac{-1}{\lambda}}
$$

with $p_{c}$ as the capillary pressure, $p_{e}$ as the capillary entry pressure, $s_{w}$ as wetting phase saturation, $s_{r, w}$ as residual wetting phase saturation. The pore size distribution parameter $\lambda$ determines the shape of the capillary pressure curve. Furthermore, Leverett scaling (Leverett, 1941) of capillary pressure is applied to prevent unphysical $\mathrm{CO}_{2}$ migration into regions of low permeability. Equations 1 and 2 are parameterised as listed in Table 1. 


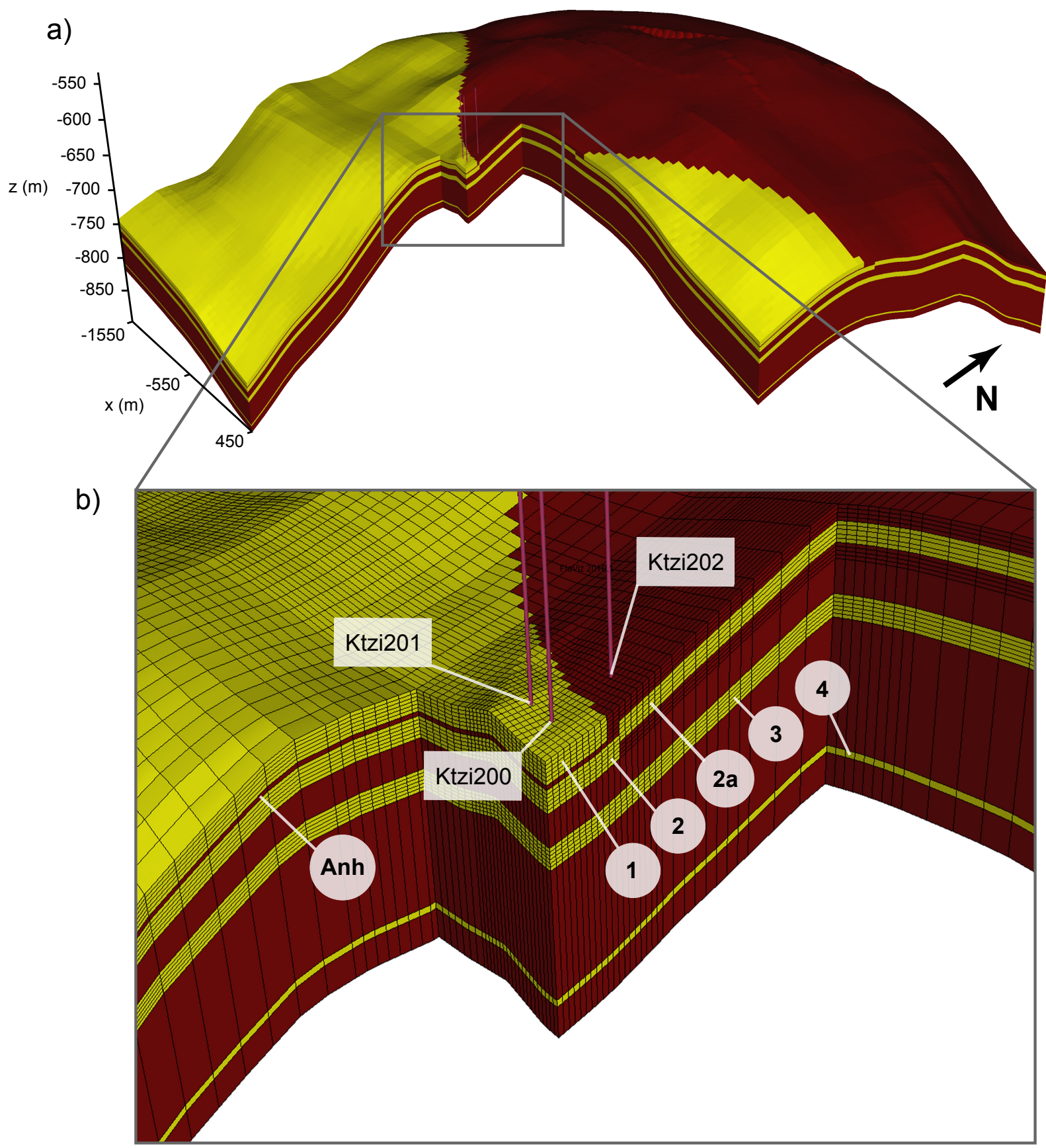

Figure 2: (a) Shape and facies distribution of the reservoir model with a horizontal extent of $5 \times 5 \mathrm{~km}$ and a model thickness of $90 \mathrm{~m}$. The upper layer consisting of mudstone facies and the southwestern part of the model are transparent. The yellow colour indicates the facies with potentially good reservoir properties predominantly formed by sandstone. The brown colour indicates the facies with poor reservoir properties consisting predominantly of mudstone. (b) Zoomed section of the near-well region. Names in circles indicate different lithological units with layer "1" and "2" as main reservoir layers, divided by the anhydrite layer "Anh". The upper layer is not present in the northern model part, the continuation of layer "2" there is called layer "2a". Layer "3" and "4" are minor reservoir layers with lower permeability. Wells are indicated by purple vertical lines. 
Table 1: Observed and initial pore function parameters.

\begin{tabular}{lcccccc}
\hline Symbol & $s_{r, w}$ & $s_{r, g}$ & $p_{e}$ & $\lambda$ & $n_{w}$ & $n_{g}$ \\
\hline Value & 0.25 & 0.1 & 0.1 bar & 1.01161 & 5 & 1.2 \\
\hline
\end{tabular}

The $\mathrm{CO}_{2}$ migration model generates the spatiotemporal distribution of $\mathrm{CO}_{2}$ that serves as the input for the geoelectrical modelling.

\subsection{Geoelectrical model}

During each iteration of the workflow described in Figure 1, several runs of the $\mathrm{CO}_{2}$ simulation are carried out, which provide spatial $\mathrm{CO}_{2}$ distributions at each timestep. With a salinity equivalent of $220 \mathrm{~g}^{-1} \mathrm{NaCl}$ (Baumann et al., 2014), the electrolytic conduction exerts the dominant effect on the electrical medium properties and the influence of pressure and surface conduction can be neglected. Reservoir temperature is constant as $\mathrm{CO}_{2}$ temperature equilibrates already in the injection well (Wiese, 2014). Therefore, the $2^{\text {nd }}$ empirical relation by Archie (1942) is applied.

$$
\frac{\rho_{t}}{\rho_{0}}=\frac{1}{S_{\mathrm{w}}(t)^{n}}=\frac{1}{\left(1-S_{\mathrm{CO}_{2}}(t)\right)^{n}}
$$

Equation 3 assumes a three-phase system with an insulating rock matrix and a mixed pore fluid of conductive brine and gaseous, resistive $\mathrm{CO}_{2}\left(S_{\mathrm{w}}+S_{\mathrm{CO}_{2}}=1\right)$ and directly links changes in saturation to changes in the electrical bulk resistivity of the medium $\frac{\rho(t)}{\rho(0)}$ under consideration of a saturation exponent $n$.

A simplified three layer model derived from induction $\operatorname{logs}$ (Kiessling et al., 2010) is used to generate the baseline $\rho_{0}$. This baseline model is laterally extrapolated to the far field. The variable near field resistivity distributions at each timestep $\rho(x, y, z, t)$ are calculated from the $\mathrm{CO}_{2}$ saturations and interpolated to a refined tetrahedral mesh used to solve the geoelectrical forward problem yielding apparent resistivity ratios for all measurement configurations as a function of time. For the sake of computational efficiency, all modelled timesteps are solved in parallel distributed over 64 CPUs using the flexible interface of the Geophysical Inversion and modelling Library (pyGIMLi) by Rücker et al. (2017). The geoelectrical forward modelling operator uses unstructured discretisations and quadratic shape functions (Rücker et al., 2006).

Rather than fixing the exponent $n$ to a specific value, the limited petrophysical data available are used to define lower and upper bounds and calibrate $n$ during the coupled inversion. A common value for sandstones of $n=2.0$ is used as the initial value and $n$ may vary between 1.6 and 2.6 which is a typical range for saturation exponents (Tiab and Donaldson, 2016) and also the range of Ketzin cores (Kummerow and Spangenberg (2011) and (Wagner and Wiese, 2018, this issue)). While this allows some flexibility to the electrical reservoir properties, the assumption of a constant saturation exponent throughout the entire reservoir remains. Geoelectrical heterogeneity is hence forced to be represented by the spatially varying distribution of gaseous $\mathrm{CO}_{2}$. The saturation exponent is the only petrophysical parameter that is calibrated during the inversion. (Wagner and Wiese, 2018, this issue) provide a detailed discussion on the saturation-dependent electrical properties for the Ketzin reservoir.

\section{Fully-coupled inversion}

\subsection{Model parameterisation}

The model is parameterised with four groups of parameters describing different physical processes. The main parameter group is the intrinsic permeability which is coupled to the porosity (Figure 1). It is spatially defined by pilot points (e.g. Certes and de Marsily, 1991). That means the permeability is estimated at selected discrete points in space and interpolated to the simulation grid, here based on linear radial basis functions. This approach is preferred over classical zonation, as it avoids sharp parameter transitions and results in a smooth permeability distribution, which is more likely to approximate the reservoir geology.

Figure 3 shows the distribution of pilot points within each layer of the underlying geological model (Figure 2).

The density of the pilot points is adjusted to the expected information density, i.e. high density close to the wells and decreasing density towards the model boundaries. The number of parameters is reduced in the lower sandstone layers (layers 3 and 4 in Figure 2), which play a minor role for $\mathrm{CO}_{2}$ migration. The horizontal and vertical model grid resolution of permeability and porosity is finer than the distance between the observation wells (50 to $112 \mathrm{~m}$ ) and the vertical electrode spacing (typically $9 \mathrm{~m})$. Generally, pilot points are set very dense such that the model is overparameterised to allow to determine the sensitive areas during the inversion.

The permeability of pilot points at the wellbore locations is constrained to a fixed ratio honouring borehole observations from field and laboratory measurements (see section subsection 2.1). Since the absolute value of these borehole measurements is subject of discussion (subsection 2.1) only the permeability ratio between the boreholes 

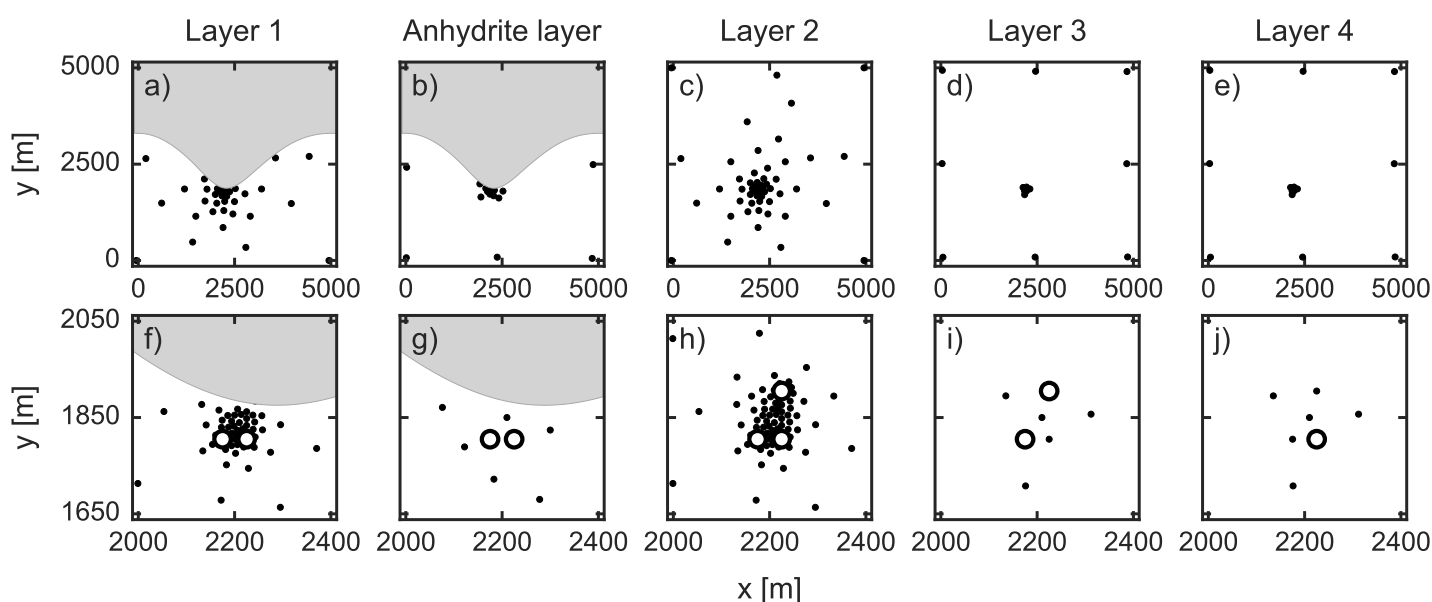

Figure 3: Layer-wise parameter resolution of the lithological units shown in Figure 2. Black dots indicate spatially distributed pilot points and white circles indicate well perforations. Grey shaded areas indicate non-existence of the respective layer. (a) The reservoir layer 1 is discretised with 158 pilot points partitioned to an upper and a lower part with 79 points each. (b) The anhydrite layer is discretised by 25 pilot points. (c) The reservoir layer 2 is discretised with 244 pilot points. Analogue to (a) it is partitioned to an upper and a lower part. (d+e) The reservoir layers 3 and 4 consist of 15 pilot points each. The pilotpoints close to the boundaries are tied to each other. The lower row (f-j) represents zoomed sections of the upper row (a-e).

is constrained. This ensures that similar geology is populated with similar permeability. All pilot points are subject to a Tikhonov regularisation (layer 1 and 2 with $100 \mathrm{mD}$, layer 3 with $30 \mathrm{md}$, layer 4 with $10 \mathrm{mD}$. These values are plausible considering pumping tests, previous models, flowthrough and NMR measurements. See also the discussion in subsection 2.1. The parameters rock compressibility, pore volume multiplier of the lateral boundaries and saturation exponent are inverted with a single value implying a homogeneous distribution.

\subsection{Data pretreatment}

The aim of data pretreatment is to enhance the models ability to match the signal in the input data and reduce the impact of structural noise. The latter always arises since the model is an imperferct representation of reality and may be increased by potential measurement errors. As shown in Figure 1, four different datasets serve as the input to the coupled inversion, specifically, the input dataset consists of 9 hydraulic time series, one $\mathrm{CO}_{2}$ pressure time series, $2 \mathrm{CO}_{2}$ arrival times (for wells Ktzi200 and Ktzi202), and 1008 electrical resistivity time series. The measured data are pretreated and become model observations.

\subsubsection{Hydraulic data}

The data are converted to the differential pressure $\Delta p_{k}$ with respect to the reference level of each observation series

$$
\Delta p_{k}=m_{k}-m_{\text {ref }}
$$

with $m_{k}$ as measured value and $m_{r e f}$ as the initial pressure. It is good practice for pumping test analysis to use the differential pressure (also called drawdown) relative to initial pressure level. Aside from technical reasons this procedure orthogonalises out measurement errors of the reference level. The model is forced to follow the dynamic which prevents a pseudo fit through the moving average of observed values (Doherty and Welter, 2010).

\subsection{2. $\mathrm{CO}_{2}$ pressure}

Observed and simulated data are converted to long and short-term differential pressure. The long term differential pressure is calculated with respect to the initial $\mathrm{CO}_{2}$ pressure, the short-term differences are calculated between each consecutive interval of equal injection rate. Doherty and Welter (2010) and Doherty (2015) recommend using differences within datasets for cancelling out structural noise. The current procedure separates the physical processes of long term reservoir pressure build up and short-term near well pressure dynamic due a well skin, which frequently occurs and may have many different reasons. This parameterisation is analogue to applying hydraulic drawdown. The model is forced to follow the dynamic which prevents a pseudo fit through the moving average of observed values (Doherty and Welter, 2010).

\subsection{3. $\mathrm{CO}_{2}$ arrival times}

Although the reservoir is multi layered, only the first arrival is available for each well. The values are directly calibrated without preconditioning. However, arrival times 
require special attention for weighting (section 3.5), may determine the model runtime (section 3.4) may prevent convergence if non-arrival model runs occur.

\subsubsection{Geoelectrical data}

For reducing structural noise, resistivities measured at a given point in time $\rho(t)$ are normalised with its corresponding baseline apparent resistivity $\rho\left(t_{0}\right)$ observed prior to $\mathrm{CO}_{2}$ injection.

$$
\rho_{a}(t)=\frac{\rho(t)}{\rho\left(t_{0}\right)}
$$

The resulting time-series of apparent resistivity ratios serve as input for the inversion. For the field application, geoelectrical data requires additional pre-processing as discussed in Wagner and Wiese (2018, this issue).

\subsection{Inversion approach}

The model is overparameterised, with the consequence that some parameters can be well defined by observation data while others remain insensitive. To counterbalance the deteriorating effect of insensitive parameters on the inversion, both Tikhonov regularisation and truncated singular value decomposition (that provides also a certain form of regularisation) are applied. The latter identifies the sensitive principal components and the corresponding super parameters based on the initial problem. By omitting the insensitive components from the linear case, the following nonlinear parameter estimation steps are sped up by factor four in the present study. This effectively reduces the dimension of overparameterised problems, as parameters without linear independent information are expressed as a linear combination of the problem dimension spanned by the super parameters. Tikhonov regularisation (in this study applied as preferred value) ensures a minimum error variance of the permeability set, i.e. that large variations from the expected value occur only when necessary to fit the observations. The observation contribution $\phi_{o}$ and the regularisation contribution $\phi_{r}$ add up to the total objective function. The weighting $\mathrm{w}_{r}$ is automatically adjusted in each iteration such that parameters insensitive to observation data receive a small weight through the regularisation to ensure that the numerical scheme remains stable.

$$
\phi=\phi_{o}+w_{r} \phi_{r}
$$

The applied inversion concept in this study is truncated singular value decomposition in combination with pilot points, following the work of Christensen and Doherty (2008).
Let $\mathbf{d}$ be a vector of multi-physical observations and let $\mathbf{m}$ be the model parameter vector. For the sake of a simpler notation, it is further assumed that there exists a linear relation between the two such that

$$
\mathbf{d}=\mathbf{G m} \text {. }
$$

Performing a singular value decomposition on $\mathbf{G}$ yields

$$
\mathbf{G}=\mathbf{U S V}^{T} .
$$

The diagonal of matrix $\mathbf{S}$ holds the singular values of $\mathbf{G}$ arranged from highest to lowest and $\mathbf{U}$ and $\mathbf{V}$ denote unitary matrices formed by data and model eigenvectors, respectively. Truncating the system by grouping the low and zero singular values into a submatrix $\mathbf{S}_{2}$ and substitution of $\mathbf{G}$ in Equation 7 leads to

$$
\mathbf{d}=\mathbf{U}\left(\begin{array}{ll}
\mathbf{S}_{\mathbf{1}} & \mathbf{S}_{\mathbf{2}}
\end{array}\right)\left(\begin{array}{c}
\mathbf{V}_{1}^{T} \\
\mathbf{V}_{2}^{T}
\end{array}\right) \mathbf{m} .
$$

Christensen and Doherty (2008) define a set of super parameters $\mathbf{m}^{\text {sup }}$ as

$$
\mathbf{m}^{\text {sup }}=\mathbf{V}_{1}^{T} \mathbf{m} .
$$

These super parameters represent a projection of the actual model parameters into the subspace spanned by the orthogonal vectors in the columns of the $\mathbf{V}_{1}^{T}$ matrix. Super parameters are factors through which parameter combinations corresponding to the chosen eigenvectors are multiplied to obtain the actual model parameters (Christensen and Doherty, 2008). The distinct advantage here is that the full Jacobian matrix has to be computed only once, whereas later (finite-difference based) sensitivity calculations are carried out for super parameters only. This significantly reduces the number of required forward simulation runs. Fifty super parameters are sufficient to capture the complexity of the synthetic model in this study, which effectively reduce the computational effort by a factor of four to five.

Estimates of the super parameters are computed as

$$
\mathbf{m}_{\text {est }}^{\text {sup }}=\left(\mathbf{S}_{\mathbf{1}} \mathbf{U}^{T} \mathbf{U} \mathbf{S}_{\mathbf{1}}\right)^{-1} \mathbf{S}_{\mathbf{1}} \mathbf{U}^{T} \mathbf{d}=\mathbf{S}_{\mathbf{1}}{ }^{-1} \mathbf{U}^{T} \mathbf{d} .
$$

After solving the reduced inverse problem, actual estimates of the model parameters at pilot point locations are derived by multiplication with $\mathbf{V}_{1}$

$$
\mathbf{m}_{\mathrm{est}}=\mathbf{V}_{1} \mathbf{m}_{\mathrm{est}}^{\text {sup }} \text {. }
$$

The inversion procedure is terminated when the decrease in the objective function stagnates, i.e. exhibits changes below $3 \%$ for at least three consecutive iterations. This usually occurred after five to eight iterations. 


\subsection{Technical aspects}

Model convergence is crucially dependent on high quality of the derivatives. A thorough technical setup is essential to avoid corrupt derivatives which are, according to our experience, the typical cause for poor convergence. As parameters are typically varied by a single digit percent range, the noise level should be significantly smaller to avoid unphysical derivatives. The numerical accuracy of the simulations has to be consistent for different model runs and partially requires higher precision than for manual simulations. We strongly recommend assuring the integrity of the derivatives by appropriate tests, e.g. visually inspecting if certain parameters have unplausible values or by use of the PEST tool JACTEST.

\subsubsection{Time stepping}

E300 is equipped with an automatic time stepping control, that adapts the time stepping to the individual problem. When model parameters are varied, the time stepping algorithm may change the number and length of the intervals with the effect that a numerical discontinuity compared to the previous model run compromises the derivatives. Therefore, the automatic time stepping was overridden such that all derivative model runs for one Jacobian matrix have identical time stepping, obtained through a scheduled prior run. By setting convergence criteria slightly tighter than the automatically chosen value for the base run, it is ensured that there is no need for reducing time steps later during the derivative runs. On the other side, some convergence criteria, such as residuals during linear and non linear iterations, could be modified to save runtime. The solution is then validated with a final run using Schlumberger recommended convergence criteria.

\subsubsection{Arrival times}

During model runtime a script monitors the $\mathrm{CO}_{2}$ saturation in both observation wells and terminates model execution after arrival in all wells. The drawback is that the simulation time may vary by several orders of magnitude and can become very large. Traditionally the model would be truncated at some period after the last observed arrival and setting a virtual punishment term in case the $\mathrm{CO}_{2}$ has not arrived within the simulation period. This is avoided by increasing the injection rate to a high value thirty days after the last observed arrival ensuring that arrival occurs even under unfavourable conditions. This procedure increases inversion stability through the generation of smooth derivatives and limits the runtime. As a small restriction, the arrival times are only valid before the rate increase.

\subsubsection{Discrete boundaries}

Many steps of data conversion are carried out using tools from the PEST suite, batch and Python scripts. Also these conversions need to be continuously differentiable during the Jacobian calculation. For example the inverted Brooks-Corey parameters necessarily have a tabular Eclipse input format. To avoid gridding effects compromising the derivative calculation, the tables are generated with Lagrangian intervals that are adapted to actual residual saturations.

The maximum model grid permeability is limited to $1000 \mathrm{mD}$. It is implemented as a limiting condition during the field generation, while the underlying pilot point model parameters have an upper limit of $10000 \mathrm{mD}$ thus allowing to circumvent the deteriorating effects of inversion parameters hitting their boundaries during a parameter upgrade. Further technical aspects are described in the PEST manual (Doherty, 2016).

\subsection{Observation weighting}

Multi-physical inversion is carried out with different datasets. For multi-physical inversion it is vital to keep the weighting well structured to normalise the different data and in order to obtain a balanced set of observations. Furthermore an intuitive modellers understanding is beneficial to identify problematic data and estimate the contribution of different datasets. Four types of observation data are included; two types of pressure data, arrival times and geoelectrical data. Each type comprises different number of data time series e.g. 9 pressure observation series for hydraulic tests, two $\mathrm{CO}_{2}$ arrival times, or 1008 geoelectrical resistivity series. Each of these series then comprises a number of individual observations. Each series may have individual duration and amplitude, each individual observation may have different intervals from the previous and the following.

The objective function components $\phi_{o}$ and $\phi_{r}$ from Equation 6 are calculated as the sum of the weighted squared residuals

$$
\phi_{o, r}=\sum_{i=1}^{n}\left(w_{i} r_{i}\right)^{2} .
$$

with $n$ as the total number of observation/regularisation values and $r_{i}$ is the residual defined as the difference between observed/regularised and simulated values. The individual weighting factors $w_{i}$ are calculated with a hierarchical approach

$$
w_{i}=\sqrt{w_{\text {type }}} \sqrt{w_{\text {series }}} w_{j}
$$

The first component $w_{\text {type }}$ determines the weight of the data type (e.g. pressure or arrival time). 
The second component $w_{\text {series }}$ accounts for the number of series within each data type and is calculated as

$$
w_{\text {series }}=\frac{1}{n_{\text {series }}}
$$

The third component $w_{j}$ weights the individual observations within each series

$$
w_{j}=\sqrt{\frac{\Delta t_{j}}{\sum_{k=1}^{m}\left(y_{k}-y_{\mathrm{ref}}\right)^{2} \Delta t_{k}}}
$$

with $m$ as the number of observations in each series, $y$ is the observed value and $y_{\text {ref }}$ is the reference observation representing the undisturbed system state, e.g. as 0 for drawdown (4) or 1 for apparent resistivity ratios.

The interval $\Delta t$ is the time for which each observation is representative and calculated from the observation interval

$$
\Delta t_{k}=\frac{t_{k+1}-t_{k-1}}{2}
$$

with $t_{k+1}$ and $t_{k-1}$ indicating the times of the following and previous observation. For the first and last observations they become $t_{k}$, respectively. Hydraulic and geoelectrical observations are introduced as time series.

The arrival times and pressure are introduced as individual incidents with equal weight, whereby $\Delta t$ has an arbitrary, identical value for all observations. While equation 16 yields an identical objective function contribution for identical residuals, the arrival times should have higher weight for lower magnitude of observed values to provide an identical objective function contribution for the same mismatch ratio, applying a modified $\mathrm{w}_{j}$ as

$$
w_{j}=\sqrt{\frac{\Delta t_{j}}{\left|y_{k}-y_{\mathrm{ref}}\right| \sum_{k=1}^{m} \Delta t_{k}}},
$$

with $y_{\text {ref }}=0$.

The goodness of fit for each observation data type can be directly read from the objective function value. From equations 13 to 17 it follows that $100 \%$ mismatch of observations, as e.g. modelled values with $y_{\text {mod }}=y_{\text {ref }}$, results in an objective function contribution of 1 , for the respective data type. The value decreases with the square of the residuals, e.g. if all observations have a misfit of $10 \%$, the contribution to the objective function is $10^{-2}$. We propose to generally choose $w_{\text {type }}$ identically for each data type, to balance the calibration contribution of the multi-physical components.
Table 2: Objective function components of the initial and the inverted model.

\begin{tabular}{llll}
\hline Observation type & Symbol & Initial & Inverted \\
\hline Hydraulic & $\phi_{\text {hyd }}$ & $2.110^{-2}$ & $7.810^{-5}$ \\
$\mathrm{CO}_{2}$ pressure & $\phi_{\mathrm{p}}$ & $1.910^{-3}$ & $2.510^{-4}$ \\
$\mathrm{CO}_{2}$ arrival & $\phi_{\text {arr }}$ & $1.810^{-2}$ & $1.310^{-5}$ \\
Geoelectrical & $\phi_{\text {ert }}$ & $1.210^{-1}$ & $2.110^{-3}$ \\
\hline Sum observation & $\phi_{\mathrm{o}}$ & $1.610^{-1}$ & $2.410^{-3}$ \\
Regularisation & $w_{\mathrm{r}} \phi_{\mathrm{r}}$ & $7.810^{-5}$ & $4.910^{-5}$ \\
\hline
\end{tabular}

\subsection{Synthetic case study}

The inversion procedure is tested with a synthetic case study. A forward model with the main features of the Ketzin field site is set up. The aquifer structure is adapted from the geological model, with the modification that aquifers $1,2,2 \mathrm{a}$ are vertically homogeneous. The permeability and porosity distribution is generated in a sequential Gaussian simulation for each of the four aquifers and a hydraulic barrier is manually added in layer 1 between wells Ktzi200 and Ktzi201. In this case study, the relative permeability parameters are not included in the inversion. The boundary conditions as hydraulic pumping rates and $\mathrm{CO}_{2}$ injection rates are identical to the field situation. The starting model is homogeneous with $100 \mathrm{mD}$ for aquifers $1,2,2 \mathrm{a}$ and $30 \mathrm{mD}$ for aquifers 3 and 4 . To provide a realistic setup the observation dataset is generated based on the structure of the field dataset, synthetic data is generated and inverted only for times and locations where Ketzin field observations exist.

The inversion is carried out with the above described approach. The observation objective function $\phi_{o}$ decreases by factor 67 (Table 2). A substantial decrease for each observation data type was obtained although the initial objective function contributions vary by two orders of magnitude.

The normalisation in the weighting procedure allows a direct comparison of the different objective function components. The $\mathrm{CO}_{2}$ arrival data $\left(\phi_{\mathrm{arr}}\right)$ shows the best fit, probably because this type only consists of 2 observations and therefore only two degrees of freedom, while other observation data has much more data points and hence higher information content. Both pressure data $\left(\phi_{\text {hyd }}\right.$ and $\phi_{p}$ ) show a good fit, with a maximum deviation of 0.28 and 0.07 bar for hydraulic and $\mathrm{CO}_{2}$ pressure, respectively. The misfit of about 1 bar at $11^{\text {th }}$ of July (Figure $5 \mathrm{c}$ ) is an observation effect, because forward and inverse models exhibit different time stepping.

The $\phi_{\text {ert }}$ is the largest component of the observation objective function. It contributes $75 \%$ to the objective 
function before and $88 \%$ after calibration. From 1008 configurations, the 34 configurations with the highest resistivity ratio account for $75 \%$ of the $\phi_{\text {ert }} .94 \%$ of these 34 configurations have neighboured $\mathrm{AB}$ or $\mathrm{MN}$ electrodes which is a disproportionally high ratio compared to $46 \%$ in the 974 configurations with lower resistivity ratios. Configurations with small dipole lengths (neighboured electrodes) and larger spacings between current and potential electrodes represent $48 \%$ of the configurations but they have a high geometric factor and therefore contribute to $87 \%$ of $\phi_{\text {ert }}$. While $29 \%$ of the configurations include electrodes directly in the plume, these contribute $53 \%$ to $\phi_{\text {ert }}$, reflecting difficult reservoir coupling at high $\mathrm{CO}_{2}$ concentrations.

By way of example, three electrode configurations are shown in Fig. 6. Crossed bipole configurations (AM-BN) are generally more robust (Bing and Greenhalgh, 2000). This applies also to the present inversion, crossed bipole configurations form $39 \%$ of total configurations but contribute only $15 \%$ to the objective function. Single hole configurations (shown in Fig. 6c) appear to be more sensitive to near-well dynamics due to limited current penetration into the rock formation. They also show a less pronounced bias to higher objective function contributions in the inversion.

The inverted permeability reproduces the main features of synthetic model (Figure 7). Generally, the overall permeabilities of the layers are matched, with values around $100 \mathrm{mD}$ in layer 1 and 2 , and values around $30 \mathrm{mD}$ for the minor layers 16 and 23. In layer 1 a low permeability barrier (about $2 \mathrm{mD}$, yellow color) exists between wells Ktzi200 and Ktzi201. This barrier is structurally identified in the inverted model. The calibrated permeability of the barrier is around $5 \mathrm{mD}$ directly between the wells increasing to $50 \mathrm{mD}$ in a larger distance which results in a higher connectivity between the wells. Although pilot points are dense enough to represent the structure and regularisation does not impose a smooth permeability, the achieved resolution appears as limited by field observations. The overestimated permeability between the wells in turn induces overestimated permeability on the opposite side of the wells. This is a typical compensation artefact for cross hole pumping tests, since a connectivity reduction between two wells has a similar effect on the well pressure as an increase in the opposite direction (Leven and Dietrich, 2006). The permeability of the confining anhydrite is only slightly lower than the true synthetic model value of $0.025 \mathrm{mD}$.

The contribution of regularisation is negligible for the initial model (table 2) and gains relative importance for the calibrated model. It is in the order of magnitude as for hydraulic pressure and $\mathrm{CO}_{2}$ arrival. Nevertheless, regularisation predominantly affects the parameters, which are not sensitive to observation data. A detailed study about qualifying and quantifying the worth of different observation data types and regularisation methods on subsets of model parameters is beyond the scope of this study. Nevertheless, it is highly relevant to select future monitoring and modelling methods for $\mathrm{CO}_{2}$ storage.

The geoelectrical saturation exponent is calibrated to 2.02 , which is close to the true synthetic model value of 2 . The parameter is sensitive to the calibration data and not regularised.

In a model variant the relative permeability was included in the inversion through $C_{i}$ for $\mathrm{CO}_{2}$ from 1 . The initial value was 0.5 and the calibration result was with 1.006 very close to the real value of 1 . The observation objective function was slighlty higher with $2.810^{-3}$. This suggests that relative permeability can also be determined by the current model setup.

\section{Conclusions}

A fully coupled inversion framework is developed that facilitates inverse reservoir modelling based on multi-physical observation datasets. The multi-physical dataset consists of four different observation types from different measurement methods which have different ranges, units and measurement intervals. The dataset is normalised such that each observation data type has an equal contribution to the objective function. As a side effect, the calibration quality of the different physical models and data can be directly compared. To reduce structural noise that is incurred by a model's inability to represent all details of a simulated system, pressure data are preconditioned as differential pressure and geoelectrical data are preconditioned as apparent resistivity ratios.

The inversion is based on the singular value decomposition dimensionality reduction leading to reduced computational effort and therefore allows introduction of overparameterisation. The inversion relies on the PEST suite, the framework runs stable and results in a very well calibrated model.

The main geological features such as overall layer permeability and a hydraulic barrier between two wells could be calibrated. Compared to individual inversions or even manual calibration, the model inherent non-uniqueness could be significantly reduced and the main reservoir parameters could be determined, wherefore the presented framework may be a suitable way for analysis of complex and highly 

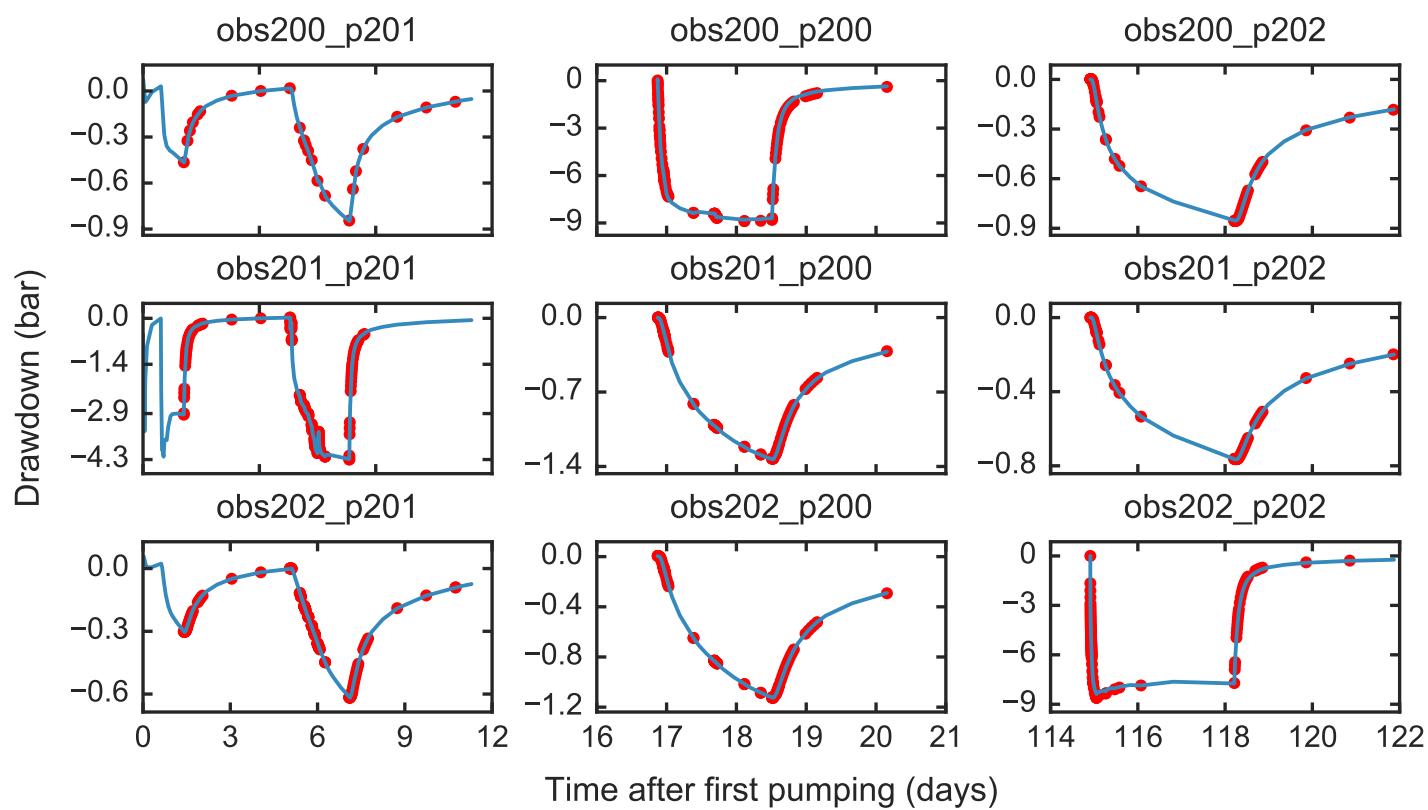

Figure 4: Hydraulic drawdown for three cross hole pumping tests of the synthetic forward model (red dots) and the corresponding inverse model (blue curve). In each plot title, "obs" denotes the observation well and "p" the pumping well. The geometrical layout can be seen in Figure Figure 2.
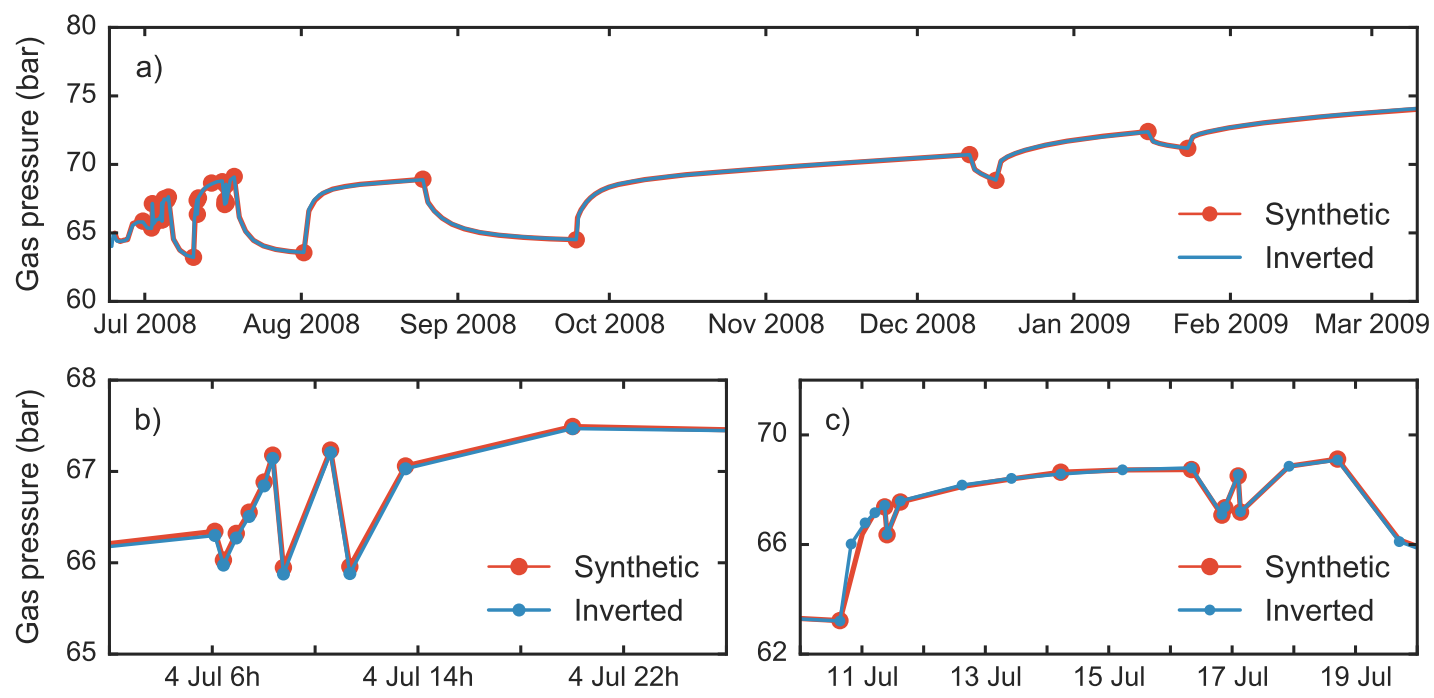

Figure 5: Bottomhole pressure of $\mathrm{CO}_{2}$ injection well Ktzi201 of the synthetic forward model (red curve) and the corresponding inverse model (black curve). Part a) shows the entire duration and part b) and c) zoom to times with a high well switching intensity and rapid pressure changes. 
a)

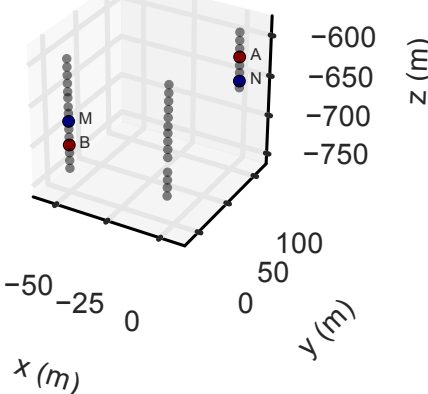

b)

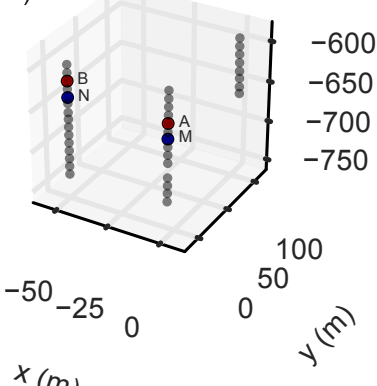
$x(m)$

c)

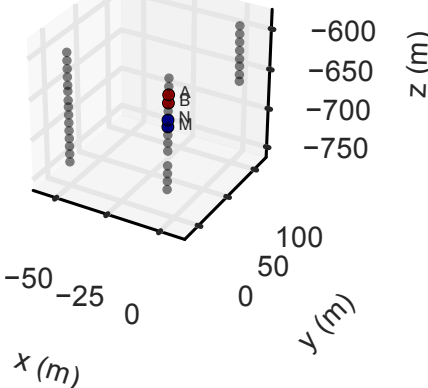

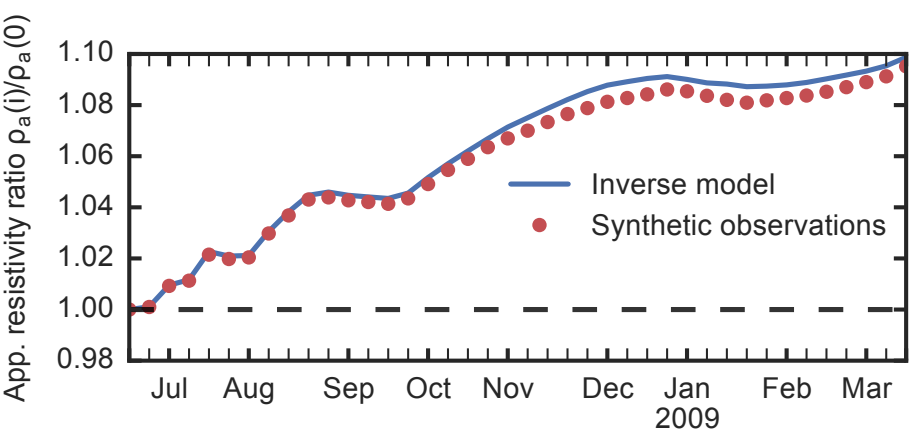
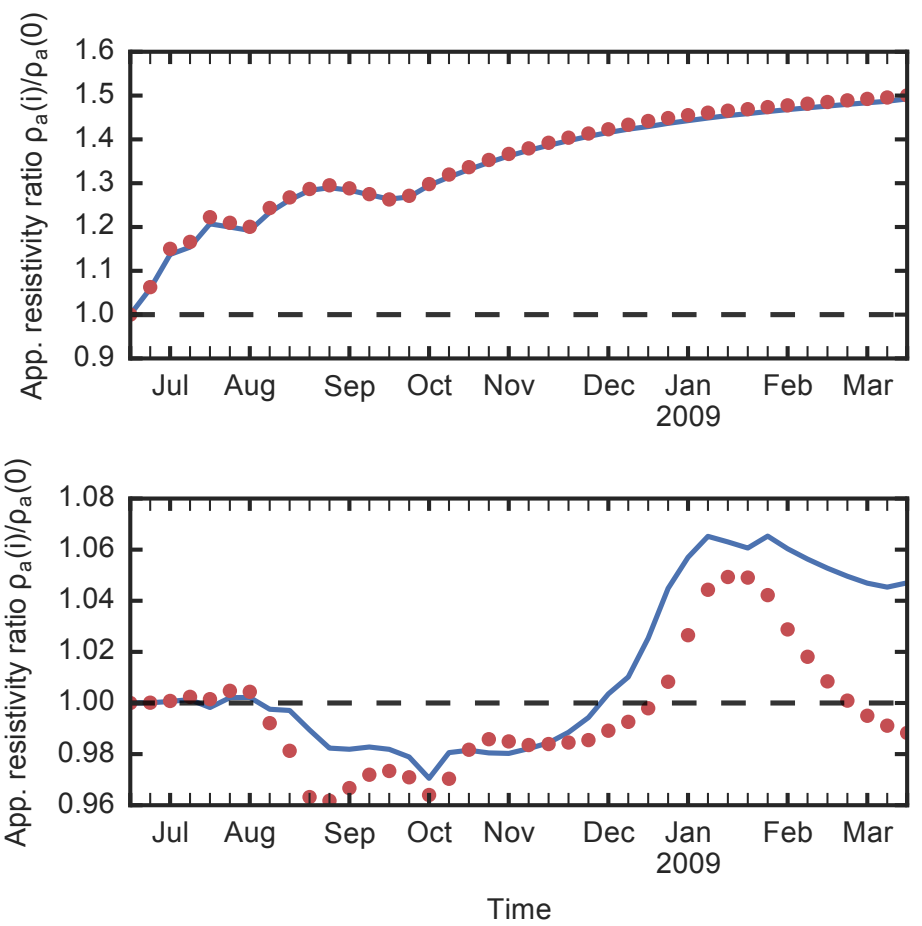

Time

Figure 6: Typical geometric electrode configurations of Ketzin measurements (left-hand side) and associated fit of synthetic input and predicted apparent resistivity ratios over time (right-hand side). 


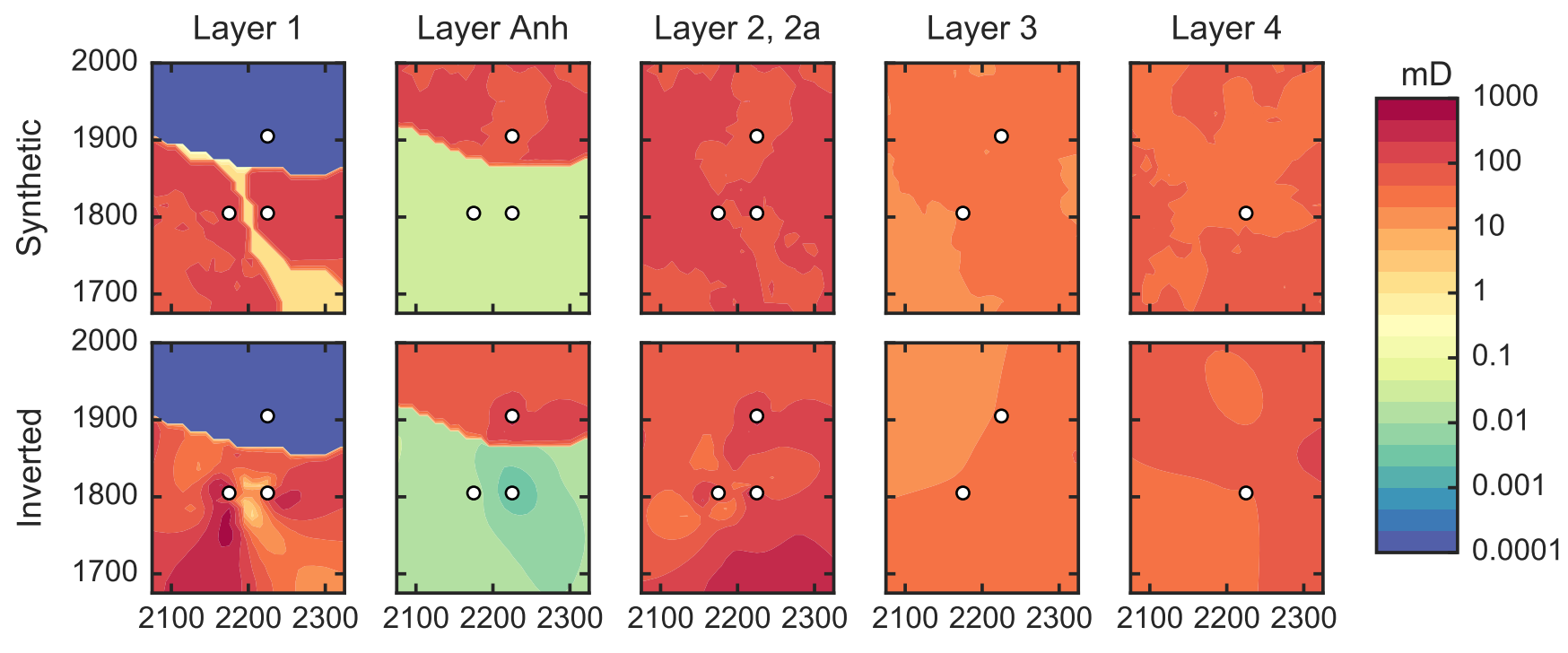

Figure 7: Permeability distribution of the synthetic forward model. The aquifer shape is adapted from the geological model. The synthetic permeability distributions are generated independently of the pilotpoints with a geostatistical approach.

instrumented field sites. Although the inversion conditions for the synthetic case study are very favorable, the barrier is only weakly reproduced because the multi-layer geological structure which is a typical feature of $\mathrm{CO}_{2}$ storage sites and other reservoirs introduces a high degree on non-uniqueness. The crosshole electrical resistivity array adds spatiotemporal sensitivity to $\mathrm{CO}_{2}$ saturation between wells and thereby is an important contribution to reduce the non-uniqueness.

However, the non-uniqueness will grow if calibration is carried out with field data and more parameters such as relative permeability functions will be included. Although the presented framework is adapted to the measurement instrumentation and geological features of the Ketzin $\mathrm{CO}_{2}$ storage site, the data pretreatment, inversion approach, and observation weighting workflow are applicable for a wide range of multi-physical monitoring scenarios. A field study for the Ketzin storage site is presented in a follow-up contribution to demonstrate the real world applicability of the developed workflow (Wagner and Wiese, 2018, this issue).

\section{Acknowledgements}

The research leading to these results received funding from the European Community's Seventh framework Programme (ENERGY.2013.5.2.1) under grant agreement No. 608608 ("Mitigation and remediation of $\mathrm{CO}_{2}$ leakage"), the Helmholtz Alberta Initiative (HAI) and the project COMPLETE by the German Federal Ministry of Education and Research. We thank John Doherty, the author of PEST, for his insightful comments during a visit at GFZ Potsdam and the reviewers for their constructive criticism.

\section{References}

Archie, G.E., 1942. The electrical resistivity log as an aid in determining some reservoir characteristics. Transactions of the American Institute of Mining, Metallurgical and Petroleum Engineers (Trans AIME) 146, 54-62. doi:10.2118/942054-G.

Baumann, G., Henninges, J., DeLucia, M., 2014. Monitoring of saturation changes and salt precipitation during $\mathrm{CO}_{2}$ injection using pulsed neutron-gamma logging at the Ketzin pilot site. International Journal of Greenhouse Gas Control 28, 134-146. doi:10 . 1016/j.ijggc.2014.06.023.

Beutler, G., 2002. Keuper-Mächtigkeit und Lithofazies des Schilfsandsteins, in: Stackebrandt, W., Manhenke, V. (Eds.), Atlas zur Geologie von Brandenburg im Maßstab 1:1,000,000.. Landesamt für Geowissenschaften und Rohstoffe Brandenburg, Germany, pp. 62-63.

Bing, Z., Greenhalgh, S., 2000. Cross-hole resistivity tomography using different electrode configurations. Geophysical Prospecting 48, 887-912. doi:10.1046/j.1365-2478.2000.00220.x.

Binley, A., Hubbard, S.S., Huisman, J.A., Revil, A., Robinson, D.A., Singha, K., Slater, L.D., 2015. The emergence of hydrogeophysics for improved understanding of subsurface processes over multiple scales. Water Resources Research 51,3837-3866. doi:10.1002/ 2015 WR017016.

Binley, A., Kemna, A., 2005. DC resistivity and induced polarization methods, in: Rubin, Y., Hubbard, S.S. (Eds.), Hydrogeophysics. Springer Netherlands. volume 50, pp. 129-156. doi:10.1007/ 1-4020-3102-5 textunderscore5.

Camporese, M., Cassiani, G., Deiana, R., Salandin, P., Binley, A., 2015. Coupled and uncoupled hydrogeophysical inversions using ensemble kalman filter assimilation of ERT-monitored tracer test data. Water Resources Research 51, 3277-3291. doi:10.1002/ 2014 wr016017. 
Carrigan, C., Yang, X., LaBrecque, D.J., Larsen, D., Freeman, D., Ramirez, A.L., Daily, W., Aines, R., Newmark, R., Friedmann, J., Hovorka, S., 2013. Electrical resistance tomographic monitoring of $\mathrm{CO}_{2}$ movement in deep geologic reservoirs. International Journal of Greenhouse Gas Control 18, 401-408. doi:10.1016/j.ijggc . 2013.04.016.

Certes, C., de Marsily, G., 1991. Application of the pilot point method to the identification of aquifer transmissivities. Advances in Water Resources 14, 284-300. doi:10.1016/0309-1708(91) $90040-U$.

Chadwick, R.A., Noy, D.J., 2015. Underground $\mathrm{CO}_{2}$ storage: demonstrating regulatory conformance by convergence of history-matched modeled and observed $\mathrm{CO}_{2}$ plume behavior using Sleipner timelapse seismics. Greenhouse Gases: Science and Technology 5, 305-322. doi:10.1002/ghg.1488.

Christensen, N., Sherlock, D., Dodds, K., 2006. Monitoring $\mathrm{CO}_{2}$ injection with cross-hole electrical resistivity tomography. Exploration Geophysics 37, 44-49. doi:10.1071/EG06044.

Christensen, S., Doherty, J., 2008. Predictive error dependencies when using pilot points and singular value decomposition in groundwater model calibration. Advances in Water Resources 31, 674-700. doi:10.1016/j.advwatres.2008.01.003.

Class, H., Mahl, L., Ahmed, W., Norden, B., Kühn, M., Kempka, T., 2015. Matching pressure measurements and observed $\mathrm{CO}_{2}$ arrival times with static and dynamic modelling at the Ketzin storage site. Energy Procedia 76, 623-632. doi:10.1016/j.egypro. 2015.07 .883$.

Doetsch, J., Kowalsky, M.B., Doughty, C., Finsterle, S., Ajo-Franklin, J.B., Carrigan, C.R., Yang, X., Hovorka, S.D., Daley, T.M., 2013. Constraining $\mathrm{CO}_{2}$ simulations by coupled modeling and inversion of electrical resistance and gas composition data. International Journal of Greenhouse Gas Control 18, 510-522. doi:10.1016/j . ijggc.2013.04.011.

Doherty, J., 2015. Calibration and Uncertainty Analysis for Complex Environmental Models - PEST: complete theory and what it means for modelling the real world. Watermark Numerical Computing.

Doherty, J., 2016. PEST - Model-Independent Parameter Estimation User Manual Part 1: PEST, SENSAN and Global Optimisers. Technical Report 6th Edition. Watermark Numerical Computing.

Doherty, J., Welter, D., 2010. A short exploration of structural noise. Water Resources Research 46, W05525. doi:10.1029/ 2009 WR008377.

Floris, F., Bush, M., Cuypers, M., Roggero, F., Syversveen, A.R., 2001. Methods for quantifying the uncertainty of production forecasts: A comparative study. Petroleum Geoscience 7, S87-S96. URL: https://www.scopus.com/inward/record. uri?eid=2-s2.0-0034976210 \&partnerID=40\&md5= 71304989 bb 86 f0a2d149d991596£978.

Förster, A., Norden, B., Zinck-Jørgensen, K., Frykman, P., Kulenkampff, J., Spangenberg, E., Erzinger, J., Zimmer, M., Kopp, J., Borm, G., Juhlin, C., Cosma, C.G., Hurter, S., 2006. Baseline characterization of the $\mathrm{CO}_{2}$ SINK geological storage site at Ketzin, Germany. Environmental Geosciences 13, 145-161. doi:10.1306/ eg.02080605016.

Herckenrath, D., Fiandaca, G., Auken, E., Bauer-Gottwein, P., 2013. Sequential and joint hydrogeophysical inversion using a fieldscale groundwater model with ERT and TDEM data. Hydrology and Earth System Sciences 17, 4043-4060. doi:10.5194/ hess $-17-4043-2013$.

Hinnell, A.C., Ferré, T.P.A., Vrugt, J.A., Huisman, J.A., Moysey, S., Rings, J., Kowalsky, M.B., 2010. Improved extraction of hydrologic information from geophysical data through coupled hydro- geophysical inversion. Water Resources Research 46, W00D40. doi:10.1029/2008wr007060.

Jenkins, C., Chadwick, A., Hovorka, S.D., 2015. The state of the art in monitoring and verification - Ten years on. International Journal of Greenhouse Gas Control 40, 312-349. doi:10.1016/j.ijggc . 2015.05 .009 .

Kempka, T., Kühn, M., Class, H., Frykman, P., Kopp, A., Nielsen, C., Probst, P., 2010. Modelling of $\mathrm{CO}_{2}$ arrival time at Ketzin - Part I. International Journal of Greenhouse Gas Control 4, 1007-1015. doi:10.1016/j.ijggc.2010.07.005.

Kiessling, D., Schmidt-Hattenberger, C., Schütt, H., Schilling, F.R., Krüger, K., Schöbel, B., Danckwardt, E., Kummerow, J., 2010. Geoelectrical methods for monitoring geological $\mathrm{CO}_{2}$ storage: First results from cross-hole and surface-downhole measurements from the $\mathrm{CO}_{2} \mathrm{SINK}$ test site at Ketzin (Germany). International Journal of Greenhouse Gas Control 4, 816-826. doi:10.1016/j.ijggc. 2010.05.001.

Kowalsky, M.B., Gasperikova, E., Finsterle, S., Watson, D., Baker, G., Hubbard, S.S., 2011. Coupled modeling of hydrogeochemical and electrical resistivity data for exploring the impact of recharge on subsurface contamination. Water Resources Research 47, W02509. doi:10.1029/2009wr008947.

Kummerow, J., Spangenberg, E., 2011. Experimental evaluation of the impact of the interactions of $\mathrm{CO}_{2}-\mathrm{SO}_{2}$, brine, and reservoir rock on petrophysical properties: A case study from the Ketzin test site, Germany. Geochemistry, Geophysics, Geosystems 12, Q05010. doi:10.1029/2010GC003469.

Lengler, U., Lucia, M.D., Kühn, M., 2010. The impact of heterogeneity on the distribution of $\mathrm{CO} 2$ : Numerical simulation of $\mathrm{CO} 2$ storage at Ketzin. International Journal of Greenhouse Gas Control 4, 1016-1025. doi:10.1016/j.ijggc.2010.07.004.

Leven, C., Dietrich, P., 2006. What information can we get from pumping tests?-comparing pumping test configurations using sensitivity coefficients. Journal of hydrology 319, 199-215. doi:10.1016/ j.jhydrol.2005.06.030.

Leverett, M., 1941. Capillary behavior in porous solids. Transactions of the American Institute of Mining, Metallurgical and Petroleum Engineers (Trans AIME) 142, 152-169. doi:10.2118/ 941152-g.

Li, R., Reynolds, A., Oliver, D., 2003. History matching of three-phase flow production data. SPE Journal , 328-340.

Loke, M., Chambers, J., Rucker, D., Kuras, O., Wilkinson, P., 2013. Recent developments in the direct-current geoelectrical imaging method. Journal of Applied Geophysics 95, 135-156. doi:10 . 1016/j.jappgeo.2013.02.017.

Lüth, S., Ivanova, A., Kempka, T., 2015. Conformity assessment of monitoring and simulation of $\mathrm{CO}_{2}$ storage: A case study from the Ketzin pilot site. International Journal of Greenhouse Gas Control 42, 329-339. doi:10.1016/j.ijggc.2015.08.005.

Norden, B., Föster, A., Vu-Hoang, D., Marcelis, F., Springer, N., Le Nir, I., 2010. Lithological and petrophysical core-log interpretation in $\mathrm{CO}_{2} \mathrm{SINK}$, the European $\mathrm{CO}_{2}$ onshore research storage and verification project. SPE Reservoir Evaluation \& Engineering 13, 179-192. doi:10.2118/115247-PA.

Norden, B., Frykman, P., 2013. Geological modelling of the triassic Stuttgart formation at the Ketzin $\mathrm{CO}_{2}$ storage site, Germany. International Journal of Greenhouse Gas Control 19, 756 - 774. doi:10.1016/j.ijggc.2013.04.019.

Oliver, D.S., Chen, Y., 2010. Recent progress on reservoir history matching: a review. Computational Geosciences 15, 185-221. doi:10.1007/s10596-010-9194-2.

Pamukcu, Y., Hurter, S., Frykman, P., Moeller, F., 2011a. Dynamic 
simulation and history matching at Ketzin (CO2SINK). Energy Procedia 4, 4433-4441. doi:10.1016/j.egypro.2011.02. 397.

Pamukcu, Y., Hurter, S., Jammes, L., Vu-Hoang, D., Pekot, L., 2011 b. Characterizing and predicting short term performance for the In Salah Krechba field CCS joint industry project. Energy Procedia 4, 3371-3378. doi:10.1016/j.egypro.2011.02.259.

Peng, D.Y., Robinson, D.B., 1976. A new two-constant equation of state. Industrial and Engineering Chemistry: Fundamentals 15, 5964. doi:10.1021/i160057a011.

Ramirez, A.L., Newmark, R.L., Daily, W.D., 2003. Monitoring carbon dioxide floods using electrical resistance tomography (ERT): Sensitivity studies. Journal of Environmental and Engineering Geophysics 8, 187-208. doi:10.4133/JEEG8.3.187.

Rinaldi, A., Rutqvist, J., 2013. Modeling of deep fracture zone opening and transient ground surface uplift at kb-502 $\mathrm{co}_{2}$ injection well, in salah, algeria. International Journal of Greenhouse Gas Control 12,155-167. doi:10.1016/j.ijggc.2012.10.017.

Rücker, C., Günther, T., Spitzer, K., 2006. Three-dimensional modelling and inversion of dc resistivity data incorporating topography - I. Modelling. Geophysical Journal International 166, 495-505. doi:10.1111/j.1365-246X.2006.03010.x.

Rücker, C., Günther, T., Wagner, F.M., 2017. pyGIMLi: An opensource library for modelling and inversion in geophysics. Computers and Geosciences 109, 106-123. doi:10.1016/j. cageo . 2017.07 .011$.

Schlumberger, 2015. Eclipse 2015.2 Industry-Reference Reservoir Simulator, Technical description. Technical Report.

Schmidt-Hattenberger, C., Bergmann, P., Labitzke, T., Wagner, F., Rippe, D., 2016. Permanent crosshole electrical resistivity tomography (ERT) as an established method for the long-term $\mathrm{CO}_{2}$ monitoring at the Ketzin pilot site. International Journal of Greenhouse Gas Control 52,432-448. doi:10.1016/j.ijggc.2016.07. 024.

Seiler, A., Evensen, G., Skjervheim, J.A., Hove, J., Vabo, J.G., 2009. Advanced reservoir management workflow using an EnKF based assisted history matching method. SPE Reservoir Simulation Symposium, 2-4 February, The Woodlands, Texas , - .

Strandli, C.W., Mehnert, E., Benson, S.M., 2014. $\mathrm{CO}_{2}$ plume tracking and history matching using multilevel pressure monitoring at the Illinois Basin - Decatur project. Energy Procedia 63, 4473-4484. doi:10.1016/j.egypro.2014.11.483.

Tiab, D., Donaldson, E., 2016. Petrophysics. Theory and Practice of Measuring Reservoir Rock and Fluid Transport Properties. 4 ed., Elsevier.

Vilamajó, E., Queralt, P., Ledo, J., Marcuello, A., 2013. Feasibility of monitoring the Hontomín (Burgos, Spain) $\mathrm{CO}_{2}$ storage site using a deep EM source. Surveys in Geophysics 34, 441-461. doi:10 . 1007/s10712-013-9238-y.

Wagner, F., Wiese, B., 2018. Fully Coupled Inversion on a MultiPhysical Reservoir Model - Part II: The Ketzin case. International Journal of Greenhouse Gas Control 75, 273-281. doi:10.1016/ j.ijggc.2018.04.009.

Wiese, B., 2014. Thermodynamics and heat transfer in a $\mathrm{CO}_{2}$ injection well using distributed temperature sensing (DTS) and pressure data. International Journal of Greenhouse Gas Control 21, 232 - 242. doi:10.1016/j.ijggc.2013.12.009.

Wiese, B., Böhner, J., Enachescu, C., Würdemann, H., Zimmermann, G., 2010. Hydraulic characterisation of the Stuttgart formation at the pilot test site for $\mathrm{CO}_{2}$ storage, Ketzin, Germany. International Journal of Greenhouse Gas Control 4, 960-971. doi:10.1016/j . ijggc.2010.06.013.
Würdemann, H., Möller, F., Kühn, M., Heidug, W., Christensen, N., Borm, G., Schilling, F., 2010. $\mathrm{CO}_{2}$ SINK - From site characterisation and risk assessment to monitoring and verification: One year of operational experience with the field laboratory for $\mathrm{CO}_{2}$ storage at Ketzin, Germany. International Journal of Greenhouse Gas Control 4, 938-951. doi:10.1016/j.ijggc.2010.08.010.

Yang, X., Chen, X., Carrigan, C.R., Ramirez, A.L., 2014. Uncertainty quantification of $\mathrm{CO}_{2}$ saturation estimated from electrical resistance tomography data at the Cranfield site. International Journal of Greenhouse Gas Control 27, 59-68. doi:10.1016/ j. i jggc . 2014.05 .006$.

Zemke, K., Liebscher, A., 2017. Petrophysical characterization of in situ cores after $\mathrm{CO}_{2}$ injection and comparison with batch experiments of the German Ketzin pilot site. Energy Procedia 114.

Zhu, C., Zhang, G., Lu, P., Meng, L., Ji, X., 2015. Benchmark modeling of the sleipner $\mathrm{CO}_{2}$ plume: Calibration to seismic data for the uppermost layer and model sensitivity analysis. International Journal of Greenhouse Gas Control 43, 233-246. doi:10.1016/j . ijggc.2014.12.016. 